\title{
ESTUDO DA COMERCIALIZAÇÃO DO MAMÃO EM BRASÍLIA-DF ${ }^{1}$
}

\author{
GENI RODRIGUES FAGUNDES², OSVALDO KIYOSHI YAMANISHI ${ }^{3}$
}

\begin{abstract}
RESUMO- Estudaram-se os principais fatores envolvidos na comercialização do mamão em 10 supermercados e 9 varejões de BrasíliaDF, em janeiro de 1999. O levantamento dos dados foi realizado através da aplicação de questionários aos responsáveis pelos estabelecimentos. Os atacadistas da CEASA-DF, foram os principais fornecedores dos estabelecimentos analisados. O grau de perda dos frutos foi considerado muito alto apenas pelos varejões. A má qualidade do fruto, demora entre compra e venda, transporte precário e condições climáticas foram as principais causas de perdas segundo os varejões. Nos supermercados, foram: falta de armazenamento apropriado, má qualidade do fruto, condições climáticas e manuseio do cliente. Na maioria dos estabelecimentos, o mamão é entregue pelo fornecedor em caixas de madeira. Os mamões ficam expostos para venda em prateleiras na maioria dos estabelecimentos analisados.
\end{abstract}

Termos para indexação: comercialização, mamão, supermercados, varejões.

\section{PAPAYA COMMERCIALIZATION STUDY IN BRASÍLIA-DF}

\begin{abstract}
The main factors involved in the commercialization of papaya in 10 supermarkets and 9 retail shops of Brasília-DF was studied in January of 1999. The data was colleted using questionnaire answered by the manager of the establishment. It was observed that the wholesalers of Federal District Wholesale Market (CEASA-DF) are the main supplier of papaya in all establishment analyzed. The fruit loss was considered very high only in the retail shops. The poor quality of fruit, the delay between purchasing and selling, precarious transport system and climatic condition were the main reasons of losses attributed by the retail shops. In the supermarkets the lack of appropriate storage, poor quality of purchased fruit, climatic conditions and manipulation by clients were considered as the main causes for the losses. The supplier delivers the papaya in wood boxes in almost all establishments. Papaya fruits for selling were displayed in racks in most of the establishments analyzed.
\end{abstract}

Index terms: commercialization, papaya, supermarkets, retail shops.

\section{INTRODUÇÃO}

O Brasil é o segundo maior produtor mundial de frutas, tendo produzido, em 1998, cerca de 39,3 milhões de toneladas. Na produção mundial de mamão, o Brasil ocupa o $1^{\circ}$ lugar, com 1,76 milhão de toneladas (FAO, 1998).

A comercialização é definida como o processo final do sistema produtivo, devendo, portanto, ser compensadora para que haja estímulo, satisfação e retroalimentação do mesmo (Alves, 1992, citado por Souza \& Torres Filho, 1997). A cadeia de comercialização de cada fruta é diferente, e vários são os componentes do mercado interno envolvidos, como: produtores, intermediários, atacadistas, CEASAS, feirantes e varejistas (supermercados, quitandas, varejões e outros), que completam a distribuição aos consumidores. Existem diversos canais de comercialização de frutas no mercado interno, entre os quais: a venda direta do produtor ao consumidor, sem nenhum intermediário; do produtor ao varejista (supermercado, quitanda, feirante e outros); do produtor ao atacadista de destino, instalado próximo ao centro de abastecimento, e do produtor ao atacadista de origem, localizado junto à zona de produção. Portanto, o produtor pode decidir por uma destas alternativas, escolhendo aquela que melhor se adapte às suas condições.

No Brasil, a estrutura de comercialização de frutas ainda é inadequada, pois quase sempre o produtor não é associado a cooperativas para comercializar a sua produção, ficando na dependência do intermediário, o que afeta tanto os preços quanto a qualidade do produto. Seria importante a formação de um sistema de comercialização adequado e mais organizado, haja vista que grande parte das perdas de frutas ocorre após saírem das propriedades, até atingirem os consumidores finais (Souza \& Torres Filho, 1997). De acordo com o Ministério da Agricultura do Abastecimento e Reforma Agrária, o Brasil perde, anualmente, mais de 1 bilhão de dólares de frutas e hortaliças, sendo as porcentagens estimadas de perdas de mamão em 23,7\%. Apesar do grande volume de produtos no mercado interno, sua comercialização é limitada, pois estes são altamente perecíveis e manuseados sob condições ambientais que aceleram a perda de qualidade (Brasil, 1993).

Para que sejam adotadas técnicas que visem a melhorar

1 (Trabalho 256/2000). Recebido: 24/11/2000. Aceito para publicação: 09/11/2001. Parte da tese do primeiro autor apresentada à Universidade de Brasília, para a obtenção do grau de "Magister Scientiae".

2 Eng. Agr. MS., Faculdade de Agronomia e Medicina Veterinária da Universidade de Brasília. Bolsista DTI do CNPq. E-mail: genifagundes@bol.com.br

3 Eng. Agr. PhD, Professor Adjunto II da Faculdade de Agronomia e Medicina Veterinária da Universidade de Brasília. Bolsista de Pesquisa 2C do CNPq. Campus Universitário Darcy Ribeiro, Caixa Postal 04508, CEP 70.910-970, Brasília, DF. E-mail: kiyoshi@unb.br 
o sistema de comercialização, torna-se fundamental conhecer alguns fatores que contribuem para a formação deste processo. Como os supermercados e varejões estão ocupando um espaço cada vez maior na comercialização de frutos, buscando atualizar seu sistema de comercialização para atender às exigências cada vez maiores dos consumidores, realizou-se a presente pesquisa com o objetivo de estudar os principais fatores envolvidos na comercialização do mamão em supermercados e varejões do Plano Piloto, Brasília-DF.

\section{MATERIAL E MÉTODOS}

A pesquisa foi desenvolvida em Brasília, no mês de janeiro de 1999. O universo adotado para a realização deste estudo foi composto por diversos estabelecimentos (supermercados e varejões) localizados no Plano Piloto.

De acordo com a ASBRA, existem dez supermercados no Plano Piloto que são considerados como matrizes. Portanto, visitaram-se todas as matrizes para o estudo. Como esta associação garantiu que da mesma forma que os frutos são apresentados nas matrizes e são apresentados em suas filiais, semelhantemente não houve necessidade de fazer uma amostragem para os supermercados. Já para os varejões/sacolões, foi realizada uma amostragem aleatória simples e constatou-se que 9 destes estabelecimentos seriam representativos da amostra.

Os supermercados foram divididos em pequeno, médio e grande porte. Esta divisão foi fornecida pela Associação de Supermercados de Brasília (ASBRA), que estabelece o porte do estabelecimento em metros quadrados, sendo pequenos (0$\left.500 \mathrm{~m}^{2}\right)$; médios $\left(501-5.000 \mathrm{~m}^{2}\right)$ e grandes $\left(5001-15.000 \mathrm{~m}^{2}\right)$. Foram enviados questionários aos 10 supermercados (pequeno, médio e grande porte) e aos 9 varejões do Plano Piloto, Brasília-DF, para obter informações sobre fornecedores do mamão, prazo para pagamento, fatores que baseiam os estabelecimentos ao estabelecerem os preços de venda, perdas, tipos de embalagens e forma de exposição dos frutos para venda no estabelecimento.

\section{RESULTADOS E DISCUSSÃO}

\section{Fornecedores do mamão comercializado}

A CEASA-DF, é a principal fornecedora de mamão tanto para os varejões quanto para os supermercados pesquisados (Tabela 1). Estes resultados concordam com informações contidas no Agrianual (1999), as quais confirmam que as frutas comercializadas nos supermercados são, em grande parte, adquiridas nas CEASAS. No entanto, segundo esta mesma fonte, alguns supermercados já adotam o sistema misto (CEASA e produtor) para a compra de frutas nacionais, exceto a banana e a laranja, devido ao alto volume comercializado e, no caso da banana, devido à necessidade de climatização da fruta em câmaras que custam caro.

\section{Prazo máximo para efetuar pagamento dos frutos}

O prazo para pagamento do mamão variou entre os estabelecimentos, sendo maior nos supermercados de médio e grande porte. Isto certamente é devido à maior quantidade de mamão adquirida por estes estabelecimentos. $\mathrm{O}$ mesmo acontece no Estado de São Paulo, onde o prazo para pagamento de produtos 'hortifruti' varia de 21 a 30 dias após a entrega para a maioria dos supermercados, podendo ultrapassar 40 dias nas grandes redes, que compram maiores volumes (Agrianual, 1999).

\section{Critérios adotados ao estabelecer o preço de venda do fruto}

Verificou-se que grande parte dos estabelecimentos estabelece os preços de venda do mamão baseados na época do ano, preço de aquisição e na procura dos consumidores. Um percentual de $25 \%$ dos varejões e $17 \%$ dos supermercados de grande porte não informaram.

A época do ano é um fator que realmente influencia na formação do preço do produto. Apesar de o mamão ser produzido praticamente o ano todo,nos meses mais frios e/ou chuvosos a sua produção é menor, o que leva a uma redução na oferta do fruto no mercado e conseqüente elevação no seu preço de venda. Os fatores climáticos também podem causar aumento na incidência de doenças e pragas que danificam os frutos e reduzem a produção, afetando, assim, os preços de venda do produto.

O preço de aquisição também é tido como um dos critérios adotados pelo varejista ao estabelecer os preços de venda do mamão, estando relacionado ao fator época do ano. Isto porque, em certas épocas do ano, a produção reduz e a procura pelo produto aumenta, ocasionando uma elevação do preço de aquisição do fruto.

Somente os varejões $(43 \%)$ e os supermercados de grande porte $(17 \%)$ responderam que se baseiam na qualidade do fruto ao estabelecer os preços de venda. Portanto, a maioria dos estabelecimentos pesquisados não se baseia na qualidade ao estabelecerem os preços de venda do mamão. Como foi feita uma visita a todos os estabelecimentos antes da aplicação do questionário, verificou-se que, em alguns destes, são encontrados frutos de baixa qualidade, sendo vendidos a preços relativamente altos, ou seja, o preço não condiz com a qualidade do produto. Outro fato é que, na compra do produto, muitos estabelecimentos adotam o critério qualidade para negociação de preços; no entanto, ao vendê-lo para o consumidor final, poucos se baseiam neste critério. Contudo, sugere-se que estes estabelecimentos, ao estabelecerem o preço de venda do produto, observem a qualidade, que inclui aparência, tamanho, cor, firmeza e outros aspectos, procurando oferecer ao consumidor produtos de boa qualidade.

\section{Grau de perda do fruto}

O grau de perda do mamão variou dentro do estabelecimento e entre os estabelecimentos, sendo esta considerada muito baixa apenas nos estabelecimentos de menor porte (varejões e supermercados pequenos).

A maioria dos supermercados de pequeno (67\%) e médio portes $(67 \%)$ respondeu que as perdas são baixas. O baixo índice de perdas atribuídos pelos responsáveis destes estabelecimentos pode estar relacionado a fatores como: reposição diária pelo distribuidor (no caso atacadistas da CEASA-DF) dos frutos que não foram vendidos; maior giro dos produtos e melhor forma de expor os frutos nas prateleiras.

Já as perdas consideradas médias e altas ocorreram em sua maioria nos supermercados de grande porte. Isto talvez seja em função do maior volume comercializado ou até mesmo do 
manuseio inadequado dos frutos pelos funcionários ou pelos próprios consumidores. As perdas geralmente são altas porque a quantidade de pessoas que passam por estes estabelecimentos, é maior, o que implica excesso de manuseio das frutas, na hora de escolher o produto, e também pelos funcionários, que repõem o estoque.

Apesar de os supermercados adotarem algumas estratégias para a redução das perdas, como a compra de frutos de melhor qualidade e a reposição diária do estoque das prateleiras, ainda se verifica um alto índice de perdas nestes estabelecimentos. Isto mostra que medidas mais eficientes devem ser adotadas na redução das perdas, como o treinamento de funcionários, classificação dos frutos, melhor exposição e conservação dos frutos.

Estudos sobre perdas de produtos hortícolas (hortaliças e frutas) tornam-se muito importantes, devido às características de alta perecibilidade, dos elevados custos de produção destes produtos e da sua importância econômica e alimentar (Tsunechiro et al., 1994). Estes autores estudaram as perdas de frutas no mercado varejista de São Paulo e obtiveram uma média de 12,9\% para o mamão.

A pesquisa mostrou que o percentual de perdas dos frutos variou em relação ao tipo de estabelecimento onde são comercializados; no entanto, independentemente do fato de ter sido considerado alto ou muito baixo, é importante que sejam tomados cuidados no manuseio dos frutos, procurando reduzir ainda mais a perda que geralmente acontece nesta etapa final da comercialização.

\section{Principais causas das perdas atribuídas pelos estabelecimentos}

Verificou-se que em $72,4 \%$ dos varejões foram consideradas como principais causas das perdas do mamão: a má qualidade do fruto adquirido, o transporte precário, a demora entre compra e venda e as condições climáticas. Já o restante respondeu que são a falta de armazenamento apropriado, a embalagem inadequada e o manuseio do cliente.

Dentre os supermercados de pequeno e grande portes, $25 \%$ atribuem como causas das perdas a falta de armazenamento apropriado, a má qualidade do fruto comprado e o manuseio do cliente, respectivamente. As condições climáticas também foram consideradas como causas principais das perdas do mamão por $25 \%$ dos supermercados de pequeno porte. Cerca de $25 \%$ dos supermercados de grande porte não informaram.

Dos supermercados de médio porte, cerca de 33,3\% consideram a falta de armazenamento apropriado, as condições climáticas e o manuseio do cliente, respectivamente, como causas de perdas do mamão.

Vários são os fatores relacionados às perdas de frutas na fase de comercialização. Soares (1998) cita como principais razões das perdas pós-colheita a falta de pessoal habilitado, o uso de práticas inadequadas de produção e o desconhecimento de técnicas de manuseio pós-colheita. Pesquisadores da SUDENE (1972) levantaram os índices de perdas de produtos 'hortifruti' e observaram que, para o mamão, as principais causas de perda são a demora entre a compra e a venda $(50,4 \%)$ e a má qualidade do produto comprado (25\%).

Em todos os estabelecimentos pesquisados, o manuseio dos frutos pelos clientes foi uma das principais causas de perdas na comercialização. O mesmo foi verificado por Tsunechiro et al.
(1994), mostrando assim que é fundamental que o consumidor evite causar danos ao produto que está adquirindo, sejam estes provocados por compressão, arranhões ou queda. No entanto, o manuseio inadequado dos frutos pelos consumidores pode ser conseqüência da falta de classificação e embalagem dos frutos, o que obriga estes a selecionarem os frutos na gôndola. Sendo assim, a classificação prévia dos frutos por estádio de maturação e categoria, e o acondicionamento em embalagens apropriadas evitaria o seu excessivo manuseio pelos consumidores.

Outro aspecto bastante citado pelos estabelecimentos como causa das perdas foi a má qualidade do fruto comprado. Portanto, sugere-se que os mesmos passem a exigir mais dos fornecedores em relação à qualidade do fruto que estão adquirindo e, ao receber o produto, conservá-lo adequadamente, evitando danos mecânicos e adotando medidas como: treinamento dos funcionários que manipulam as frutas, uso de embalagens adequadas, melhoria na exposição dos frutos no local de venda sem amontoá-los em prateleiras, seleção dos frutos de acordo com o estádio de maturação, tamanho, presença de danos e outras características pertinentes.

É necessário, além da produção de frutos sadios, o emprego de manuseio adequado com uso de técnicas que possibilitem reduzir as perdas visando, assim a melhorar a qualidade para comercialização. No entanto, para introduzir novas técnicas, é preciso, antes, estudar o processo de produção e comercialização de cada produto para identificar os pontos de estrangulamento dentro da cadeia. A redução das perdas na cadeia de comercialização, desde a colheita até o consumidor final, poderá significar maior ganho econômico para todos os elos deste segmento.

\section{Tipo de embalagem em que o fruto é entregue}

O uso de embalagem de madeira predominou em todos os estabelecimentos pesquisados, apesar de o mamão ser um fruto bastante frágil. No entanto, é importante que tanto o fornecedor (produtor ou atacadista) quanto os estabelecimentos responsáveis pela distribuição final tomem consciência de que o tipo de embalagem a ser utilizada deve adequar-se ao produto, além de protegê-lo, ser resistente, facilitar o transporte e manejo, melhorar o aspecto visual e ter um custo relativamente baixo.

A embalagem é um fator importante na comercialização e, para o consumidor, é sinônimo de mais comodidade e praticidade, devendo conter em seu rótulo todas as informações sobre o produto (natureza, qualidade, classificação, origem e destino). Recomenda-se, portanto, o uso de embalagem adequada e o seu manuseio correto, de acordo com o tipo de fruto e estádio de maturação do mesmo, para reduzir as perdas, aumentar a eficiência na comercialização e manter a qualidade do fruto.

\section{Maneira como os frutos são expostos para venda}

Na maioria dos varejões e supermercados de pequeno e médio portes, os mamões ficam expostos em prateleiras. Entretanto, nos supermercados de grande porte, todos colocam o mamão para venda em prateleiras. Esta forma de exposição dos frutos é a mais utilizada nos estabelecimentos varejistas; no entanto, nem sempre é a mais adequada, pois, na maioria das vezes, os frutos ficam amontoados ou formando várias camadas, sem distinção do estádio de maturação, o que favorece em muito 
TABELA 1 - Pesquisa sobre a comercialização do mamão em varejões e supermercados (pequeno, médio e grande portes) do Plano Piloto de Brasília-DF, com dados em porcentagem.

\begin{tabular}{|c|c|c|c|c|}
\hline Fornecedor & V a re jã o & Sup. pequeno & S up. m é dio & S up.grande \\
\hline C EA S A -D F & 100 & 100 & 100 & 100 \\
\hline Próprio produtor & 0 & 0 & 0 & 0 \\
\hline \multicolumn{5}{|l|}{ Prazo para pagamento } \\
\hline No mesmo dia da entrega & 22 & 33,3 & 0 & 0 \\
\hline 1 a 15 dias após a entrega & 56 & 0 & 0 & 0 \\
\hline 15 a 30 dias após a entrega & 11 & 33,3 & 67 & 0 \\
\hline $\mathrm{M}$ a is de 30 dias após a entrega & 11 & 33,3 & 33 & 75 \\
\hline \multicolumn{5}{|c|}{ C rité rios ao es tabelecer preços de venda do fruto } \\
\hline S ituação econôm ic a do estab elec im ento & 7 & 0 & 0 & 0 \\
\hline Época do ano & 29 & 25 & 33,3 & 33 \\
\hline Preço de aquisição & 14 & 25 & 33,3 & 0 \\
\hline Q ua lid ade do fruto & 43 & 0 & 0 & 17 \\
\hline Procura do consumidor & 7 & 25 & 33,3 & 33 \\
\hline \multicolumn{5}{|l|}{ Grau de perda } \\
\hline M uito baixo (até 4\%) & 22 & 33 & 0 & 0 \\
\hline B a ixo $(5$ a $10 \%)$ & 22 & 67 & 67 & 25 \\
\hline M éd io (11 a $15 \%)$ & 34 & 0 & 0 & 50 \\
\hline A lto $(16$ a $20 \%)$ & 11 & 0 & 33 & 25 \\
\hline M uito alto (acima de $20 \%$ ) & 11 & 0 & 0 & 0 \\
\hline \multicolumn{5}{|l|}{ Causas das perdas } \\
\hline F alta de armazenamento a propriado & 9,2 & 25 & 33,3 & 25 \\
\hline Embalagem inadequada & 9,2 & 0 & 0 & 0 \\
\hline Má qualidade do fruto comprado & 18,1 & 25 & 0 & 25 \\
\hline Transporte precário & 18,1 & 0 & 0 & 0 \\
\hline Demora entre compra e venda & 18,1 & 0 & 0 & 0 \\
\hline C o nd içõ es c limáticas & 18,1 & 25 & 33,3 & 0 \\
\hline M anuse io do cliente & 9,2 & 25 & 33,3 & 25 \\
\hline \multicolumn{5}{|l|}{ Embalagem em que o fruto é entregue } \\
\hline Caixa de madeira & 80 & 75 & 75 & 75 \\
\hline C a ixa p lástica & 10 & 0 & 0 & 0 \\
\hline C aixa de papelão & 10 & 25 & 25 & 25 \\
\hline A granel & 0 & 0 & 0 & 0 \\
\hline \multicolumn{5}{|l|}{ M aneira comoos frutos ficam expostos } \\
\hline Em prateleiras & 100 & 75 & 75 & 100 \\
\hline Embalagem em que foi entregue & 0 & 25 & 25 & 0 \\
\hline
\end{tabular}

o amassamento e perda da qualidade dos frutos.

Como medidas para reduzir as perdas do mamão, recomenda-se que este, primeiramente, seja selecionado por tamanho, estádio de maturação e presença de danos, podendo ser colocado em prateleiras, protegidos por papel celofane ou polietileno expandido, sem amontoá-lo ou sem formar mais de 2 camadas. No caso do mamão do grupo 'Solo', sugere-se também colocá-los em embalagens pequenas de papelão ou mesmo de madeira, com capacidade para 4 a 6 frutos no máximo, sendo cada fruto protegido com papel celofane ou polietileno expandido.

Novas formas de acomodação dos frutos nos pontos de venda devem ser estudadas, pois estes são bastante perecíveis e sensíveis aos danos provocados pelo manuseio incorreto. Por serem de grande procura na maioria dos estabelecimentos, é importante que fiquem expostos de maneira a atrair os consumidores e conservar a sua qualidade.

\section{CONCLUSÕES}

1- Os principais fornecedores de mamão para os estabelecimentos pesquisados são atacadistas da CEASA-DF.

2- Os estabelecimentos de maior porte recebem um prazo mais longo para efetuar o pagamento das frutas.

3- A maioria dos estabelecimentos não adota a qualidade como critério ao estabelecerem os preços de venda do mamão, baseando-se principalmente na época do ano, procura dos clientes e preço de aquisição do fruto.

4- O grau de perda foi considerado muito alto (acima de $20 \%$ de perda) apenas pelos varejões e alto (de 15 a $20 \%$ ) pelos supermercados de médio (33\%) e grande portes (25\%). Entre as principais causas de perdas do mamão atribuídas pelos varejões, as mais citadas foram: má qualidade do fruto adquirido, demora entre compra e venda, transporte precário e condições climáticas. Nos supermercados de pequeno, médio e grande portes foram: falta de armazenamento apropriado, má qualidade do fruto comprado, condições climáticas e manuseio do cliente.

6- Grande parte do mamão comercializado nestes estabelecimentos é entregue em caixas de madeira.

7- Os mamões ficam expostos para venda em prateleiras na maioria dos estabelecimentos pesquisados.

\section{REFERÊNCIAS BIBLIOGRÁFICAS}

ALVES, E.J. Situación del cultivo de plátano en Brasil. In: 
ASPECTOS SOCIOECONÔMICOS. Brasília: EMBRAPA-SPI, 1997. p.507-543.

ANUÁRIO DA AGRICULTURA BRASILEIRA - AGRIANUAL 1999. São Paulo: FNP, Consultoria \& Comércio, 1999. p.14-25.

BRASIL. Ministério da Agricultura, do Abastecimento e da Reforma Agrária. Perdas na Agropecuária Brasileira. Relatório preliminar da Comissão Técnica para redução de perdas na Agropecuária. Brasília: MAARA, 1993.

FAO Production Yearbook, (Roma, Itália). Disponível no site FAO http://www.faostat. Consultado em dez. 1998.

SOARES, A.G. Levantamento e identificação das perdas pós- colheita de mamão e manga comercializados na CEASA-RJ. Rio de Janeiro: EMBRAPA-CTAA, 1998. 5 p. (Projeto Finep).

SOUZA, J. da S.; TORRES FILHO, P. Aspectos socioeconômicos. In: A cultura da banana: aspectos técnicos, socioeconômicos e agroindustrias. Brasília: EMBRAPA-SPI, 1997. 585p.

SUDENE. Avaliação dos índices de perdas dos produtos Hortifruti-granjeiros comercializados na cidade do Natal. Natal: EMBRAPA, 1972. p.55.

TSUNECHIRO, A.; UENO, L.H.; PONTARELLI, C.T.G. Avaliação econômica das perdas de hortaliças e frutas no mercado varejista de São Paulo, 1991/92. Agricultura em São Paulo, São Paulo, v.41, n.2,p.1-15. 1994. 